\title{
LANDSLIDE DEFORMATION MONITORING BY THREE-CAMERA IMAGING SYSTEM
}

\author{
J. Y. Rau ${ }^{1}$, J. P. Jhan ${ }^{1} \&$ R. Andaru ${ }^{1,2}$ \\ ${ }^{1}$ Department of Geomatics, National Cheng Kung University, Taiwan - (jyrau, jyunpingjhan)@ geomatics.ncku.edu.tw \\ ${ }^{2}$ Department of Geodetic Engineering, Gadjah Mada University, Indonesia- ruliandaru@ugm.ac.id
}

KEY WORDS: Unmanned helicopter, Landslide monitoring, Three-camera imaging system

\begin{abstract}
:
Landslide deformation is a critical issue for WuWanZai as it will affect the road safety and cause transportation problem. Since the relief of this area is about 400 meters with an area of tens of hectares, we use an unmanned helicopter equipped with a three-camera imaging system to acquire high spatial resolution images in order to measure detail terrain variation. The unmanned helicopter can fly according to terrain slope to obtain $1-3 \mathrm{~cm}$ spatial resolution images. The acquired three-camera images are stitched into one perspective image in advance to construct a large format virtual image with a frame size of $34 \mathrm{~mm}$ by $78 \mathrm{~mm}$ and a FOV of $53^{\circ} \mathrm{x} 97^{\circ}$. Integrating ground control points that were measure by static GNSS continuous observation, we conduct aerial triangulation and dense point cloud generation by PhotoscanPro. We have acquired six dataset of UAV images since April 20, 2018. Then, we have conducted cloud-to-cloud distance calculation, DSM elevation difference calculation, ortho-image change analysis, photogrammetric points and GNSS stations displacement analysis, etc. In the end, from photogrammetric point displacement analysis, we have detected 1.6 meters displacement around the fourth curve of WuWanZai due to a heavy rainfall occurred at June 20. Based on the cloud-to-cloud distance analysis and DSM elevation difference results, we have observed more than 5 meters of height difference at the landslide area due to another heavy rainfall happened at Oct. 23-24. Experimental results demonstrate that by using the proposed UAV and three-camera imaging system can effectively detect landslide deformation in high accuracy.
\end{abstract}

\section{INTRODUCTION}

\subsection{Background and research motivation}

WuWanZai is locate at Tai-Road \#18, i.e. A-Li-San Road, 42K44K of Chia-Yi County, Taiwan. As shown in Figure 1, it situates at mountainous area with terrain variation more than 400 meters, thus the road was construct with five curves to reduce the slope. Due to its geological stability is low, a landslide had induced by a heavy rainfall event and cause the road collapsed with 150 meters long 10 years ago. Thus, two more curves had created to avoid the landslide area. Though the Fifth Maintenance Office of Directorate General of Highways, Taiwan had built eight underwater collection wells to reduce the water pressure in order to stop the land displacement, it is still necessary to continuously monitoring its deformation to maintain the road safety.

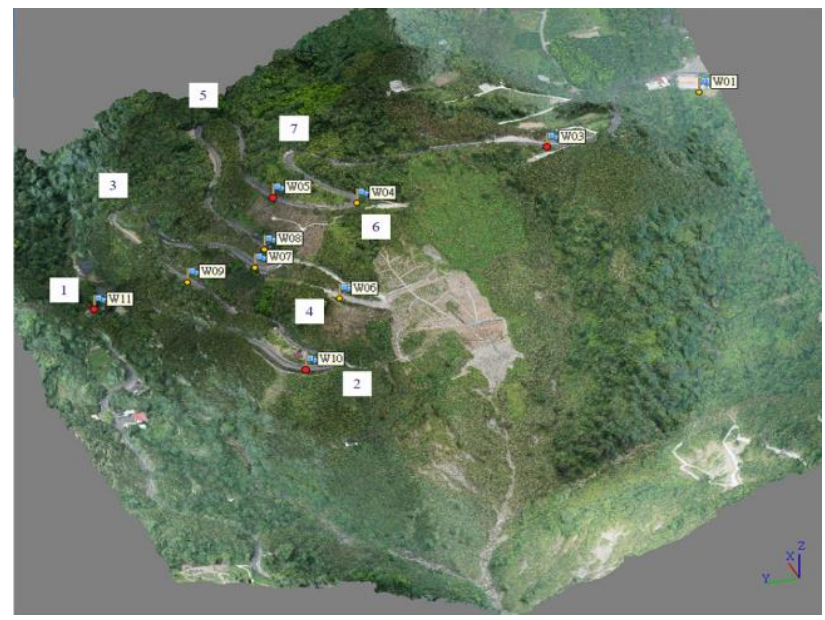

Figure 1. WuWanZai in 3D view with the location of GCPs/CKPs together with road curve number.

\subsection{Literature Review}

Many literatures that related to landslide deformation monitoring can be categorize into image-based or sensor-based methods. The most popular way of in-situ sensors are continuous GNSS observation and real-time positioning (Wang, 2013; Bellone et al, 2016; Sanlioglu et al., 2016; Mirzaee et al., 2017), geoelectrics, inclinometer, soil moisture, soil temperature (Lindner et al., 2016), and extensometer (Corominas et al., 2000), etc. The above-mentioned methods are majorly point-based measurement. While the image-based method may acquire optical imagery (Hosseini et al., 2011), Terrestrial Laser Scanning (Barbarella \& Fiani,, 2013), Terrestrial InSAR (Mazzanti et al., 2014), or radar imagery (Sara et al., 2017) are area-based surveying approach. In recent years, the UAV is getting involved in this field to carry digital camera and adopt photogrammetric and image processing techniques (Lindner et al., 2015; Peppa et al., 2016; Lindner et al., 2016; Yaprak \& Susam, 2018) for small landslides monitoring.

\section{METHODODOLOGY}

\subsection{The proposed method}

Since the relief variation of this area is more than 400 meters with an area of tens of hectares, we propose the use of an unmanned helicopter to carry a three-camera imaging system to acquire very high spatial resolution images monthly. Then, stitch every three images into one raw perspective image, conduct aerial triangulation, generate dense point clouds, DSM and ortho-image for each period, then perform deformation analysis through cloud-to-cloud distance calculation, ortho-image change analysis and DSM elevation difference.

\subsection{UAV \& three-camera imaging system}

Figure 2 and Table 1 illustrates the appearance and specification of the proposed unmanned helicopter and three-camera imaging system. One advantage of unmanned helicopter is it can take-off and landing in a vertical way, like a multi-rotatory UAV, which 
is suitable for mountain environment. Meanwhile, it has longer endurance time, i.e. 30 minutes, higher payload capacity, compare to a low cost multi-rotatory UAV. It has variable flying speed, i.e. from $0 \mathrm{~m} / \mathrm{s}$ until $30 \mathrm{~m} / \mathrm{s}$, which is also suitable for large area mapping like a fixed-wing UAV. In this study, we also design its flight path to follow the terrain variation with similar altitude (e.g. 75 and 200 meters above ground) in order to acquire similar image scale as well as high spatial resolution, i.e. GSD is about $1-3 \mathrm{~cm}$.

A raw image-stitching algorithm (Rau et al., 2016 \& Jhan et al., 2018) was developed and applied to the acquired three-camera images before aerial triangulation. The reasons to use a threecamera imaging system for data collection is its 100 degree of FOV that can cover a rather larger area to reduce the required flight time and improve the successful rate during aerial triangulation, particularly for repetitive texture and less texture area. An example of three raw images and its stitched result are display in Figure 3.

As shown in Figure 1, the distribution of road and landslide are separate at two sides. The ground control points (GCPs) and independent checkpoints (CKPs) can only be arranged along the roadside. To cope with non-well distributed control issue, the adopted unmanned helicopter is also equipped with PPK (postprocessed kinematic) to obtain controls in the air. The positional accuracy of PPK is about $20 \mathrm{~cm}$, which may not accurate enough, but better than no control.
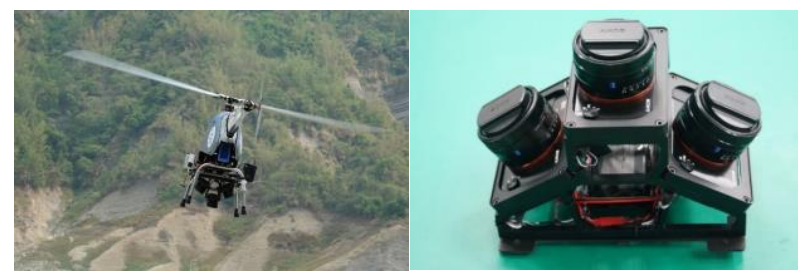

Figure 2. The adopted unmanned helicopter and three-camera imaging system.

Table 1. The specification of the used UAV and camera. Size : $1770 \mathrm{~mm} \times 330 \mathrm{~mm} \times 600 \mathrm{~mm} \quad$ Main propeller : $900 \mathrm{~mm} \times 2$ Tail propeller : $130 \mathrm{~mm} \times 2 \quad$ Empty weight : $9 \mathrm{~kg}$

\begin{tabular}{cc}
\hline Battery $: 44.4 \mathrm{~V}, 22 \mathrm{Ah}$ & Allowed wind speed $:<8$ Beaufort scale \\
\hline Max. payload weight $: 15 \mathrm{~kg}$ & Allowed Rain: drizzle \\
\hline Max. fly height: $\leqq 3000 \mathrm{~m} \mathrm{MSL}$ & Fly speed: $0 \sim 30 \mathrm{~m} / \mathrm{s}$ \\
\hline Endurance time $: 20-30 \mathrm{~min}$ (depends on payload, flying height and speed) \\
\hline Camera: SONY A7r $2 \times 3$ with $35 \mathrm{~mm}$ lens \\
\hline FOV (H x V): 96 x 53 degrees; Tilt cameras off-nadir angle: 30 degrees. \\
\hline Stitched image size $: 7600$ x 17200 , Pixel size: $4.525 \mu \mathrm{m}, \mathrm{f}=34.1 \mathrm{~mm}$ \\
\hline
\end{tabular}

\subsection{GNSS static observation of GCPs/CKPs}

For co-registration purpose, we established 11 GNSS stations by static continuous observation with 3-4 hours. Four of them highlighted in red are marked as GCPs and the others are treat as CKPs. Their distribution are depict in Figure 1 as well. The GCPs locations are chosen as outermost as possible to avoid land deformation effect. Their positions have been survey by two times, i.e. March 31 and July 31, with four months difference. Within this period, two heavy rainfall events with accumulated rainfall about $140 \mathrm{~mm}$ had occurred and induced landslide. Except for W6, which is located very close to the landslide area, has significant horizontal and vertical displacements of $6.18 \mathrm{~cm}$ and $12.4 \mathrm{~cm}$, respectively. The displacement of the others points are all under random noisy level and considered as no movement.

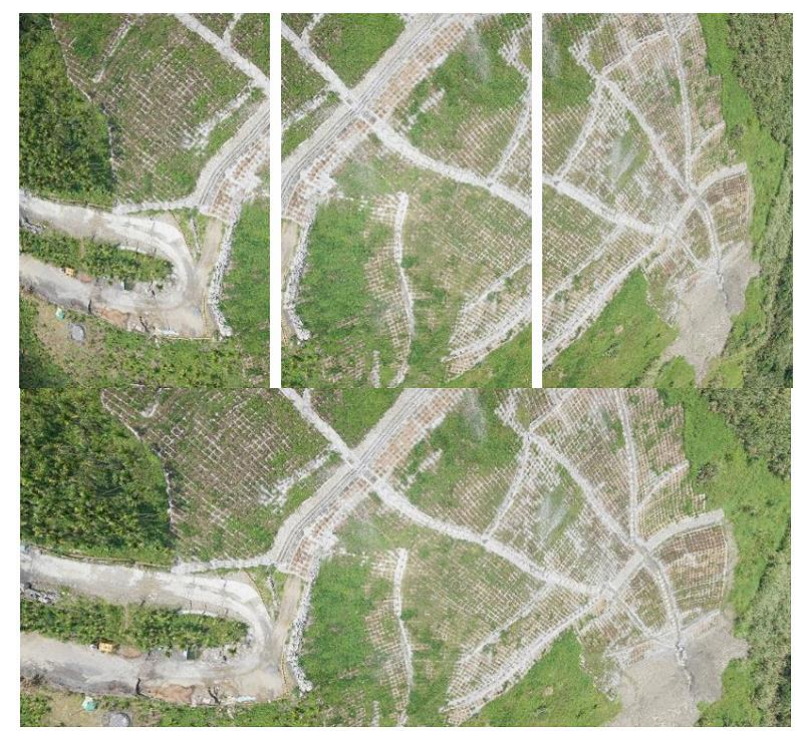

Figure 3. Sample of three-camera raw images and the stitched result.

\section{ANALYSES AND DISCUSSION}

\subsection{UAV image triangulation accuracy analysis}

In this study, we collect UAV images from April 19 until Nov. 31 , in total six dataset were obtain. After applying the developed image-stitching algorithm, we conduct aerial triangulation using Agisoft PhotoscanPro@ (renamed as Metashape $\odot$ since 2019). Table 2 demonstrates the statistics of accuracy analysis results. We design three flight-tracks to cover the whole study area. However, as shown in Table 2, April 19 has only two flights and June 30 has only one flight, due to failures of image acquisition, such as images are blurred, cloudy or too dark, etc. The other dates have three flight-paths same as Oct. $1^{\text {st }}$. The flying altitude above ground with 75 meters is to focus on the road and landslide areas with GSD $\sim 1 \mathrm{~cm}$, while the 200 meters altitude is to cover the whole study site with GSD $\sim 3 \mathrm{~cm}$.

Table 2. Statistics of aerial triangulation accuracy.

\begin{tabular}{|c|c|c|c|c|c|c|c|c|c|}
\hline \multirow{2}{*}{$\begin{array}{l}\text { Date } \\
\text { Flight \# }\end{array}$} & \multicolumn{3}{|c|}{$2018 / 4 / 19$} & \multicolumn{3}{|c|}{$2018 / 5 / 20$} & \multicolumn{3}{|c|}{$2018 / 6 / 30$} \\
\hline & 1 & 2 & & 1 & 2 & 3 & 1 & 2 & 3 \\
\hline Images \# & 314 & 297 & & 610 & 584 & 516 & 626 & 627 & 515 \\
\hline F. Overlap (\%) & 80 & 80 & & 90 & 90 & 90 & 90 & 90 & 90 \\
\hline Altitude (m) & 75 & 75 & & 75 & 75 & 200 & 75 & 75 & 200 \\
\hline GSD (cm/pixel) & 1 & 1 & & 1 & 1 & 2.65 & 1 & 1 & 2.65 \\
\hline Directions & $\mathrm{E}$ & $\mathrm{N}$ & $\mathrm{H}$ & $\mathrm{E}$ & $\mathrm{N}$ & $\mathrm{H}$ & $\mathrm{E}$ & $\mathrm{N}$ & $\mathrm{H}$ \\
\hline GCP RMS (cm) & 1.06 & 1.77 & 0.92 & 1.13 & 1.01 & 2.63 & 2.72 & 1.19 & 1.86 \\
\hline CKP RMS $(\mathrm{cm})$ & 0.98 & 1.17 & 1.91 & 0.95 & 0.87 & 1.39 & 2.11 & 1.40 & 3.33 \\
\hline $\begin{array}{l}\text { Re-projection } \\
\text { error (pixel) }\end{array}$ & & 0.92 & & & 0.86 & & & 0.72 & \\
\hline GCP/CKP \# & & $4 / 5$ & & & $4 / 6$ & & & $4 / 6$ & \\
\hline Date & & $018 / 9 /$ & & & $018 / 10$ & & & $18 / 11$ & 130 \\
\hline Flight \# & 1 & 2 & 3 & 1 & 2 & 3 & & 1 & \\
\hline Images \# & 514 & 624 & 622 & 513 & 620 & 622 & & 570 & \\
\hline F. Overlap (\%) & 90 & 90 & 90 & 90 & 90 & 90 & & 90 & \\
\hline Altitude (m) & 200 & 75 & 75 & 200 & 75 & 75 & & 200 & \\
\hline GSD (cm/pixel) & 2.65 & 1 & 1 & 2.65 & 1 & 1 & & 2.65 & \\
\hline Directions & $\mathrm{E}$ & $\mathrm{N}$ & $\mathrm{H}$ & $\mathrm{E}$ & $\mathrm{N}$ & $\mathrm{H}$ & $\mathrm{E}$ & $\mathrm{N}$ & $\mathrm{H}$ \\
\hline GCP RMS $(\mathrm{cm})$ & 1.66 & 2.35 & 1.51 & 1.45 & 1.55 & 1.53 & 1.11 & 0.78 & 2.95 \\
\hline CKP RMS (cm) & 2.24 & 1.06 & 2.64 & 2.45 & 1.38 & 2.19 & 2.76 & 1.54 & 4.76 \\
\hline $\begin{array}{l}\text { Re-projection } \\
\text { error (pixel) }\end{array}$ & & 0.74 & & & 0.69 & & & 0.68 & \\
\hline GCP/CKP \# & & $4 / 7$ & & & $4 / 7$ & & & $4 / 7$ & \\
\hline
\end{tabular}




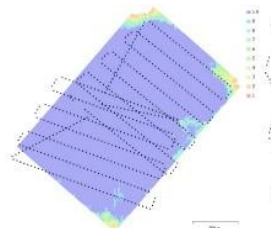

(a) $2018 / 4 / 19$

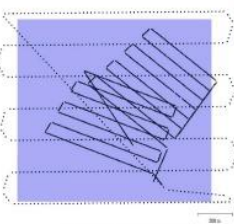

(b) $2018 / 10 / 1$

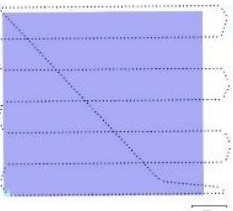

(c) $2018 / 11 / 30$

Figure 4. Flight tracks and photo positions.

During bundle adjustment, four GNSS stations are marked as GCPs (as shown in Figure 1) and the others are treat as CKPs. As illustrated in Table 2 the RMS of GCPs for all cases are smaller than $3 \mathrm{~cm}$ and the RMS of CKPs are all below $5 \mathrm{~cm}$ in both horizontal and vertical directions. The re-projection errors denotes the overall standard error of image coordinates measurement including the lens distortion. One may find out all six cases' re-projection errors are smaller than one pixel. The above analyses prove that the developed image-stitching algorithm is rigorous, accurate and stable. The stitched images fulfil the collinearity condition and feasible for high accuracy photogrammetric applications.

\subsection{Daily precipitation}

Figure 5 illustrates the daily precipitation plot between April $1^{\text {st }}$ and Dec. $30^{\text {th }}, 2018$. It can be find that two heavy rainfalls occurred at June $20^{\text {th }}$ and July $2^{\text {nd }}$ with daily precipitation about $140 \mathrm{~mm}$. Meanwhile, another heavy rainfall happened at Oct. $23^{\text {rd }}$ and Oct. $24^{\text {th }}$ had introduced a daily precipitation of $360 \mathrm{~mm}$. These three major rainfall events had affect the landslide area seriously and caused significant deformation and shallow landslide. Detail analyses results will be discuss later.

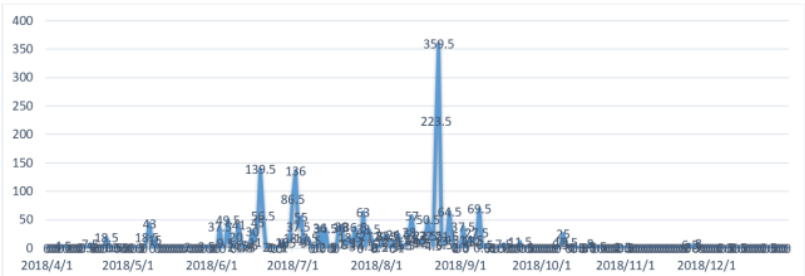

Figure 5. Daily precipitation during the study period

\subsection{GNSS stations displacement analysis}

In this study, we conducted two times of static GNSS observation, i.e. March 13 and July 31, for 3-4 hours at 11 stations. According to Figure 5, we notice that between those two dates, there are two heavy rainfalls events. Figure 6 and Figure 7 demonstrate their displacement in horizontal and vertical directions, respectively. From those two figures, comparing W6 with other stations, W6 has significant horizontal and vertical displacement. Since W6 is located very close to the landslide area and due to two heavy rainfall events that had induced land deformation, this phenomena is reasonable.

\subsection{Photogrammetric points displacement analysis}

Since the setup and measurement of GNSS stations is time consuming, this study also establish 100 photogrammetric targets along the roadside. Two examples near the landslide area are illustrate at Figure 8. They are paint in white with black background to increase the contrast for easy identify and manual measurement on the original image. After aerial triangulation, their positions can then be obtain by space intersection. Comparing two periods of results, we can conduct displacement analysis as well to increase the point-based surveying results.

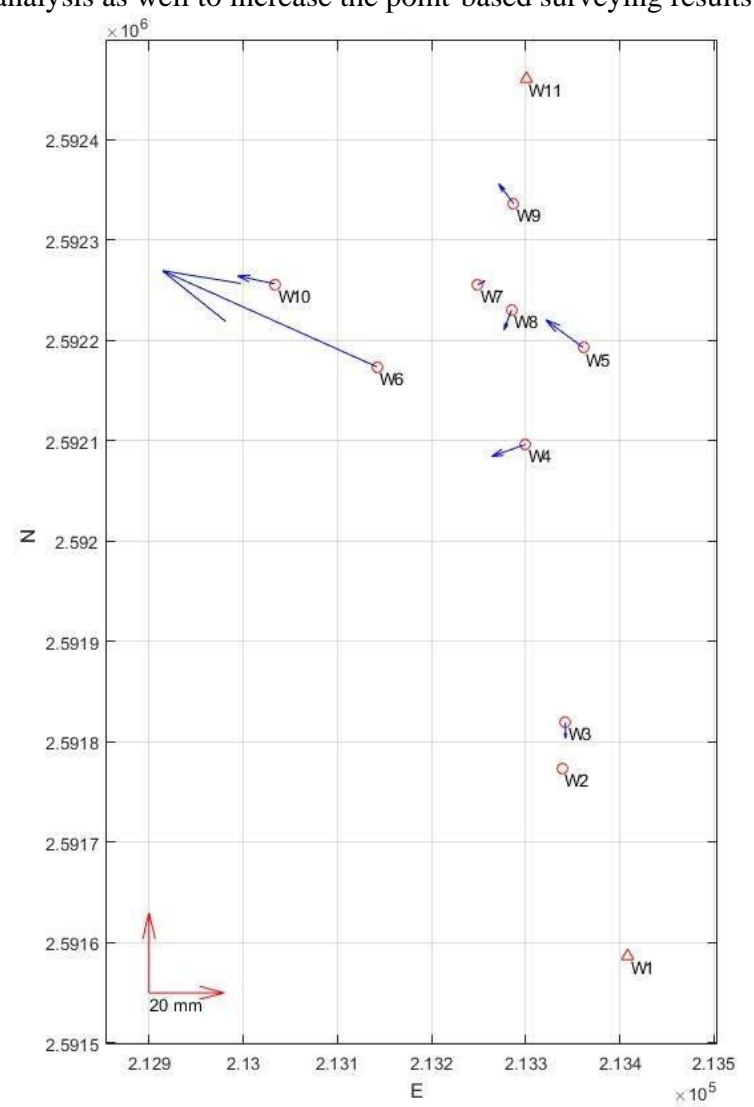

Figure 6. Horizontal displacement vector.

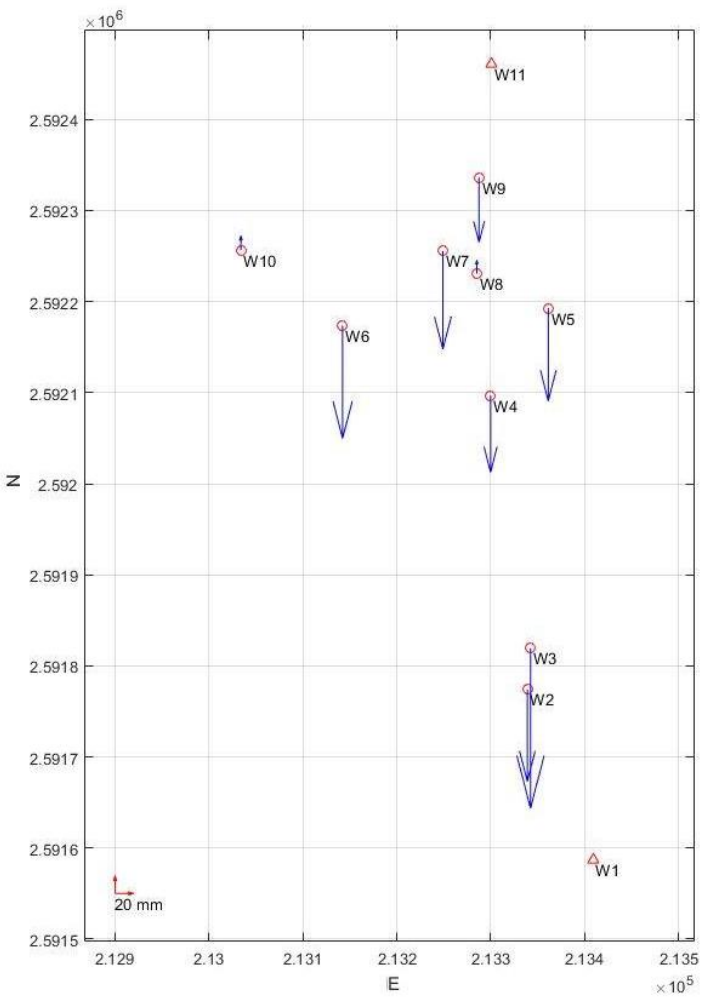

Figure 7. Vertical displacement vector. 


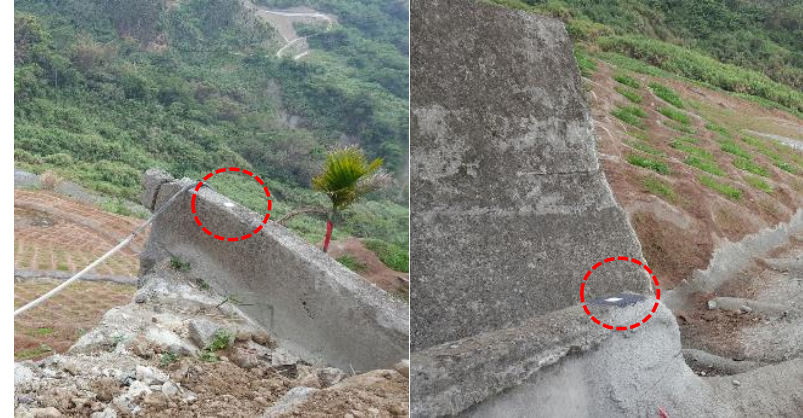

Figure 8. Photogrammetric target examples (MTP63 \& MTP64)

In this paper, two measurement results obtained from April 19 and June 30 are compare. Their displacement vectors are plot at Figure 9 and Figure 10 for horizontal and vertical directions, respectively. In which, one may observe two points that have very large displacement on both directions. They are named MTP63 and MTP64 as shown in Figure 8. Because of heavy rainfall and their locations are close to the landslide area, we obtain a horizontal displacement with $1.27 \mathrm{~m}$ and $0.99 \mathrm{~m}$ together with $0.89 \mathrm{~m}$ and $0.6 \mathrm{~m}$ of vertical offset. The other photogrammetric points also have small displacement, but not significant. This example demonstrate that utilizing photogrammetric method can compensate for the drawback of GNSS stations with lower cost.

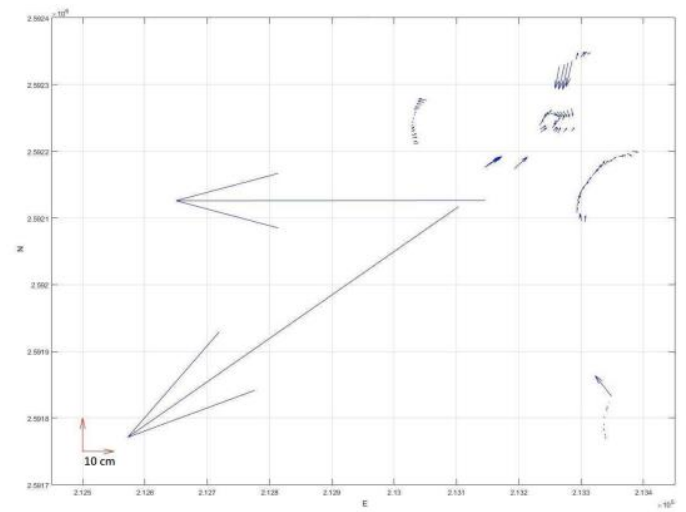

Figure 9. Horizontal displacement of photogrammetric points.

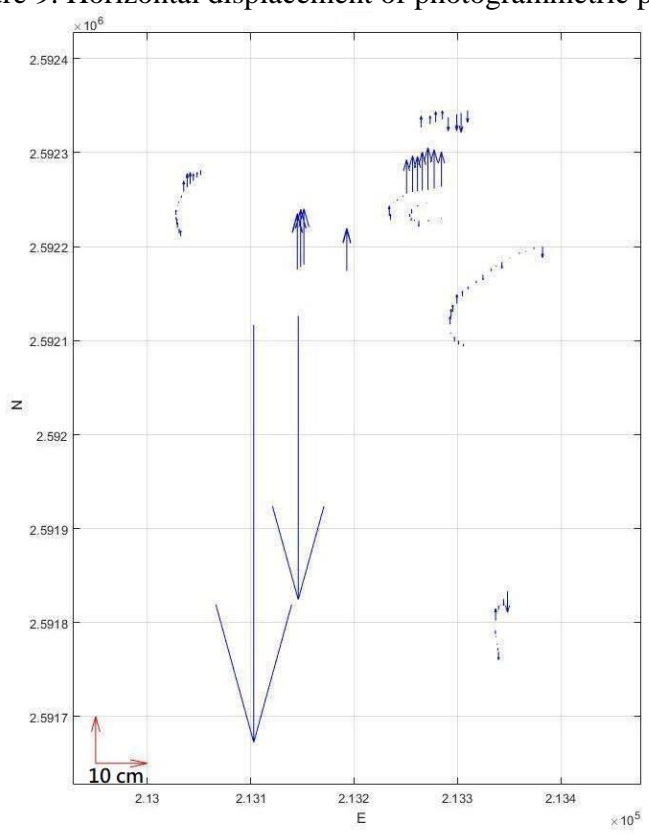

Figure 10. Vertical displacement of photogrammetric points.

\subsection{Point clouds distance analysis}

By using point-based measurement, we cannot realize the land deformation of the whole landslide area. We thus calculate the cloud-to-cloud $(\mathrm{C} 2 \mathrm{C})$ distance between two neighboured point clouds through CloudCompare $\odot$ software to investigate the land deformation situations. Figure 11 shows five $\mathrm{C} 2 \mathrm{C}$ plots for the whole six dataset in pseudo colour. The colour legend located at the right hand side depict the red colour has the maximum distance while the blue colour is the minimum one, i.e. 0 meter. The maximum distance for Figure 11(c) is 5 meters, while the other four plots are 2 meters.

First, we can observe the vegetation areas, particularly trees and miscanthus grass, have caused larger $\mathrm{C} 2 \mathrm{C}$ distance. Because the trees is erroneous in image matching and the miscanthus grass may grow up quickly in one month, we may ignore the vegetation areas. Second, the road looks no change at all, as its surface is hard without movement. It has been prove by photogrammetric point's measurement. The dense image matching also perform very well at road surface. Finally, for landslide area, we can find out there is no land deformation from Figure 11 (a) \& (e), due to no heavy rainfall had occurred between two neighboured data acquisition dates. The other three plots have shown larger $\mathrm{C} 2 \mathrm{C}$ distance, particularly for Figure 11(c) due the largest rain fall happened at Aug. 23-24. It shows that the land movement is larger than 5 meters.

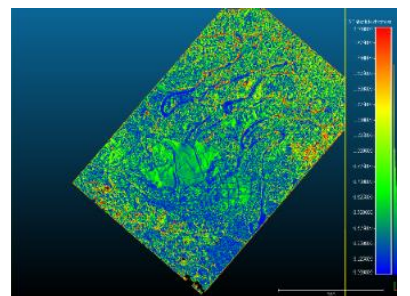

(a) May 20 vs. April 19

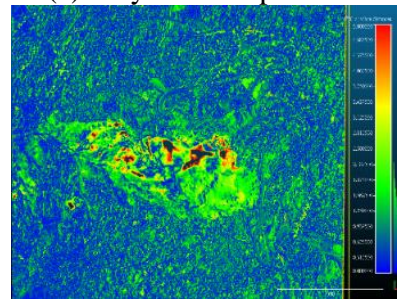

(c) Sep. 1 vs. June 30

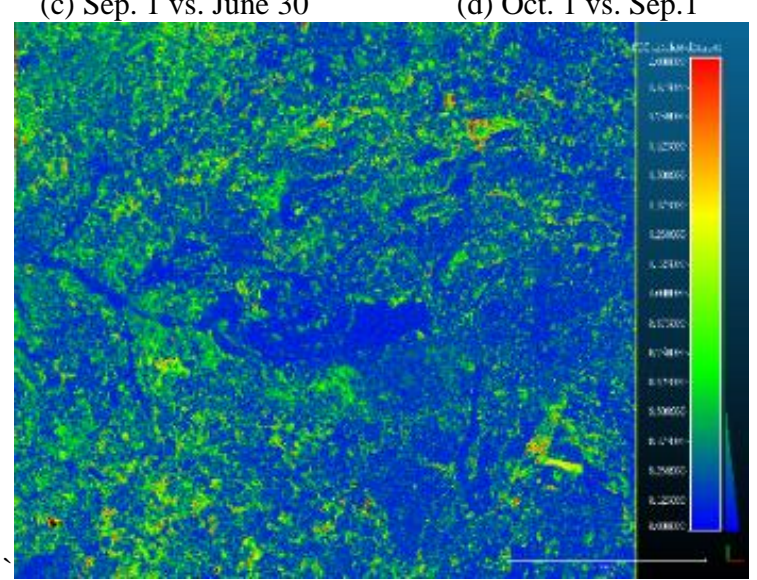

(e) Nov. 30 vs. Oct. 1

Figure 11. Point-to-point distance between two neighboured point clouds illustrated in pseudo colour. 


\subsection{Ortho-image change analysis}

The ortho-image is generally used for inspecting the land cover types. Figure 12 demonstrates six ortho-images generated by the acquired UAV images. It is easy to identify the green colour of vegetation area, brown colour of bare ground or landslide, and grey-white colour of man-made constructions or road. By look into all ortho-images in Figure 12, we notice a significant change between (c) and (d), i.e. between June 30 and Sep. $1^{\text {st }}$, due to the largest rainfall happened at Aug. 23-24. Figure 13 also illustrates four in-situ close-range photos for comparisons. Comparing Figure 13(a) \& (b), we can find out the slope protection construction has distorted due to the first rainfall event, i.e. June 20. This land deformation phenomena can be identify from Figure 11(b), but not easy to be found at Figure 12(c). Later after Aug.23-24 rainfall, the slope protection construction has almost destroyed, which can be saw from both $\mathrm{C} 2 \mathrm{C}$ plot and ortho-image. Please notice that a new slope protection construction was built at the east side of the landslide area. It can be find from Figure 13(d), within the red dashed-ellipsoid, as well.

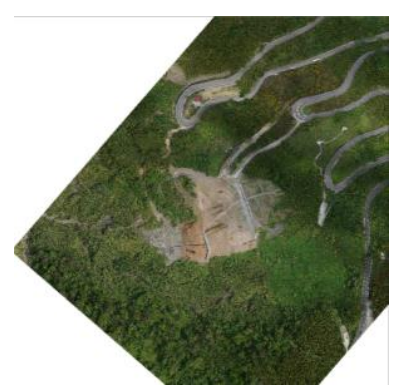

(a) April 19

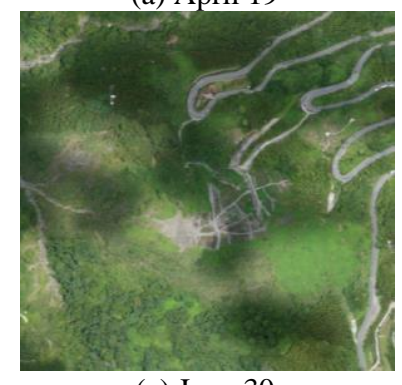

(c) June 30

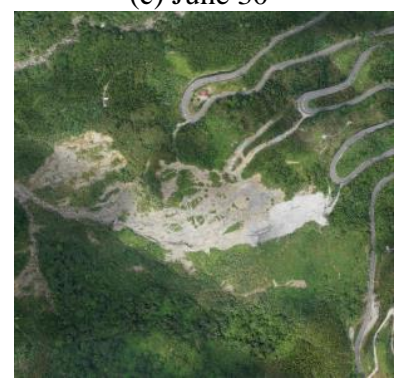

(e) Oct. 1

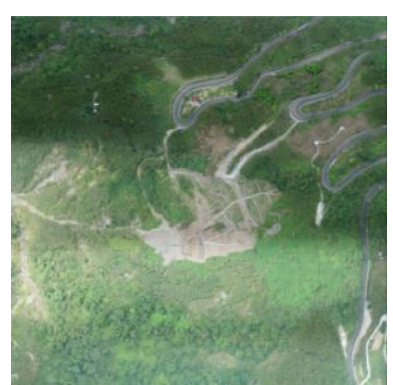

(b) May 20

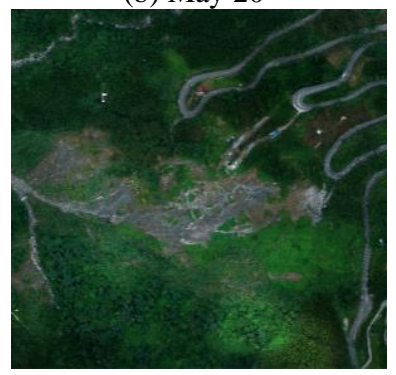

(d) Sep. 1

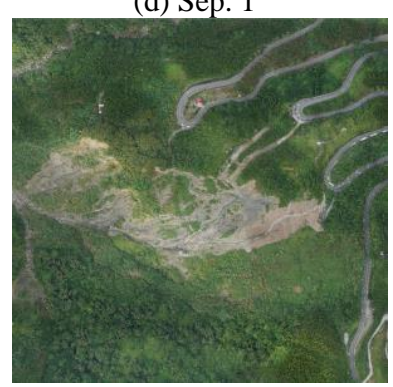

(f) Nov. 30
Figure 12.Ortho-image of each date.

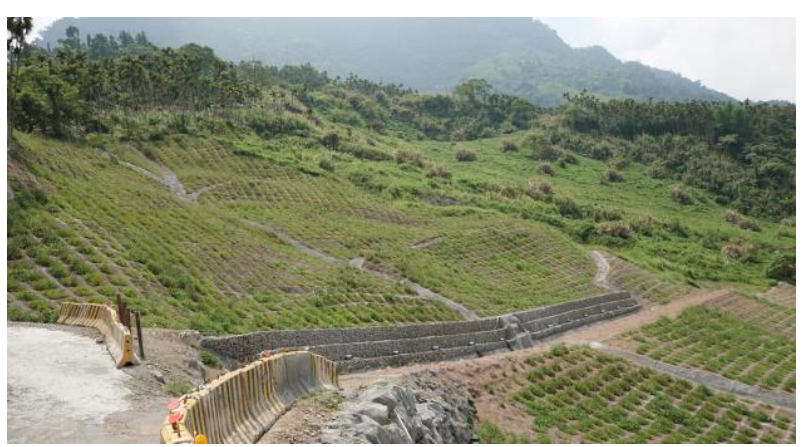

(a) May 20

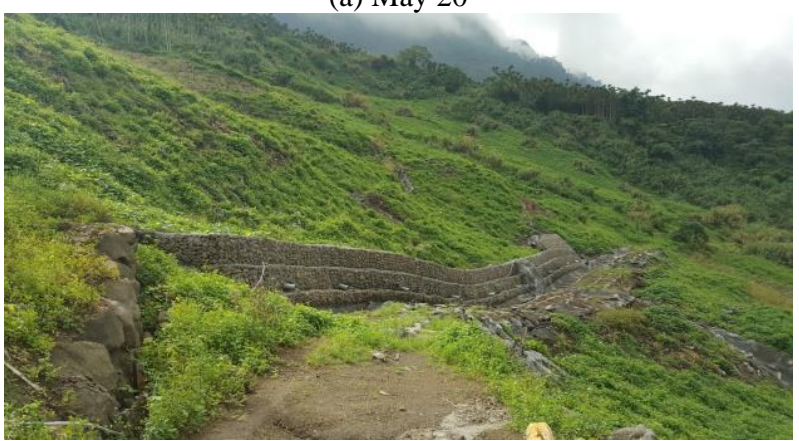

(b) July 31

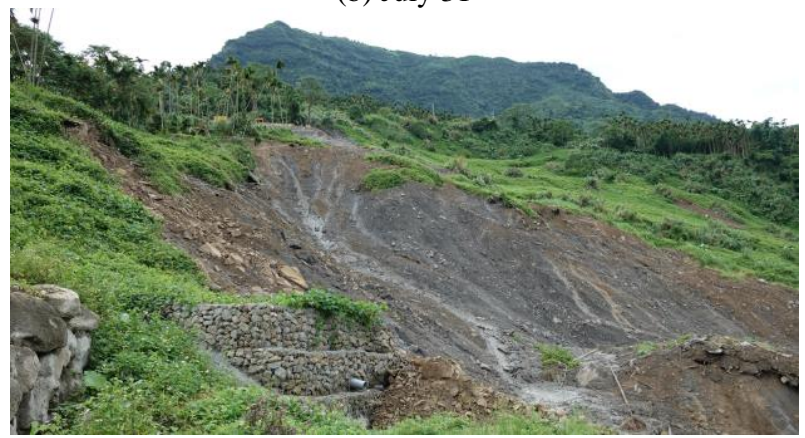

(c) Sep. 1

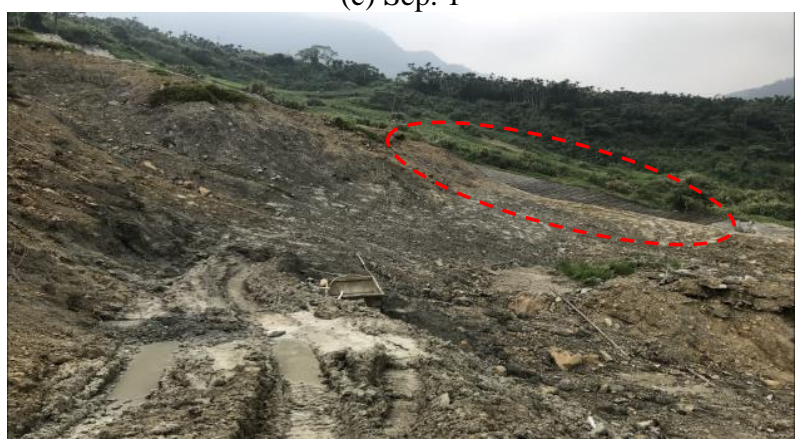

(d) Oct. 1

Figure 13. In-situ photos for different dates.

\subsection{DSM change analysis}

Figure 14 demonstrates the DSM elevation difference in pseudo colour. Please notice that the colour legend of Figure 14 (a) is different to Figure 14 (b-e). The DSM is generated by point cloud but contains only elevation information. Thus observing the DSM elevation difference, the land deformation phenomena are consistent with the $\mathrm{C} 2 \mathrm{C}$ results shown in Figure 11. However, from DSM elevation difference, we can also obtain the earth's volume change and produce soil erosion and deposition map by digitization on the raster. On the other hand, it is difficult to obtain a vector map from $\mathrm{C} 2 \mathrm{C}$ results. 


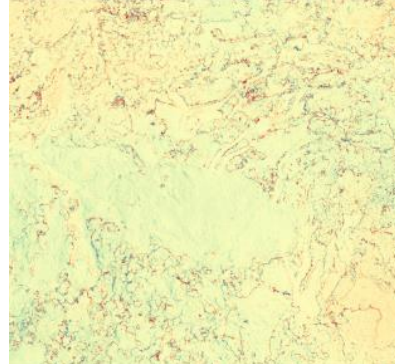

(a) May 20- April 19

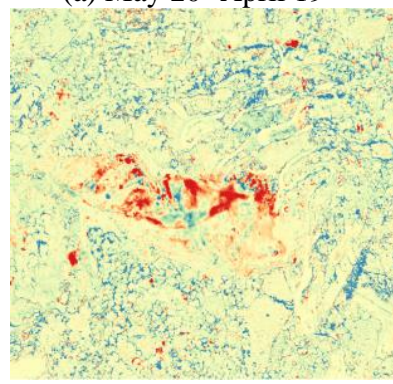

(c) Sep. 1- June 30

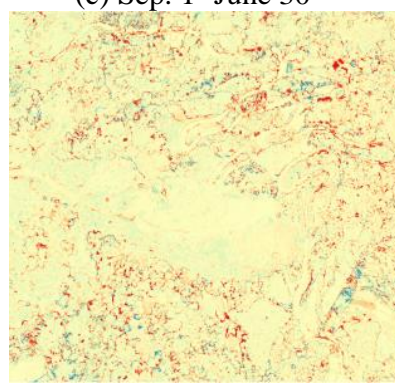

(e) Nov. 30- Oct. 1

Figure 14. DSM elevation difference between two neighbour dates.

\section{CONCLUSION}

In this study, UAV photogrammetry techniques and GIS spatial analysis tools are used for land deformation monitoring. In summary, we have obtained the following achievements and experience through this study. They are:

1. The unmanned helicopter is a mature product for surveying grade photogrammetric missions. Particularly, if it is equipped with a three-camera imaging system together assisted by the developed image-stitching algorithm. For the same mapping area with same GSD, comparing with a multiple rotary UAV equipped with a single DSLR camera, the image acquisition efficiency can be increased for more than 10 times by using the proposed system.

2. For a mountainous area, especially when the target is located at steep slope, it is recommend adopting an unmanned helicopter as it can fly slowly and follow the terrain at a certain above ground height in order to acquire images with similar image scale.

3. According to the aerial triangulation accuracy analysis results, $\mathrm{C} 2 \mathrm{C}$ results, DSM elevation differences, and orthoimage change analysis results, we have proven that the developed image-stitching algorithm is stable, reliable, reasonable and accurate that can fulfil the requirements of high accuracy photogrammetric missions.

4. The data collection procedure of GNSS continuous observation is time-consuming, but accurate (in mm level) that can be used for aerial triangulation control and real-time monitoring if a senor network can be established.
5. The photogrammetric points measurement method will obtain lower accuracy results (about $3-5 \mathrm{~cm}$ ) when compare with GNSS continuous observation method, but it is more easy to setup with lower cost. Thus, it can be consider as a complementary to densify the point-based measurement. In this study, we have observed $1.27 \mathrm{~m}$ and $0.99 \mathrm{~m}$ of horizontal displacement as well as $0.89 \mathrm{~m}$ and $0.6 \mathrm{~m}$ of vertical offset. Unfortunately, we could not setup the photogrammetric points at the landslide area for safety reason. Thus, we cannot monitor the displacement of the landslide area.

6. The photogrammetric point cloud and DSM can perform area-based land deformation monitoring. It is estimated that its positioning accuracy is within $3-10 \mathrm{~cm}$ depending on the surface types. In this study, we have found more 5 meters of $\mathrm{C} 2 \mathrm{C}$ distance or elevation difference after heavy rainfalls.

\section{ACKNOWLEDGEMENTS (OPTIONAL)}

This study was support by Ministry of Science and Technology (MOST), Taiwan, with project number 107-2119-M-006-009. The authors also like thank the support from the Fifth Maintenance Office of Directorate General of Highways, Taiwan, Land Engineering Consultant Co., LTD, UAVER and RDATA Inc.

\section{REFERENCES}

Rau, Jiann-Yeou, Jyun-Ping Jhan, Yi-Tang Li, 2016. "Development of a Large Format UAS Imaging System with the Construction of One Sensor Geometry from a Multi-Camera Array". IEEE Transaction on Geoscience and Remote Sensing, Vol. 54, No. 10, pp.5925-5934.

Jhan, Jyun-Ping, Jiann-Yeou Rau, Norbert Haala, 2018. "Robust and Adaptive Band-to-Band Image Transform of UAS Miniature Multi-lens Multispectral Camera", ISPRS Journal of Photogrammetry and Remote Sensing, Vol. 137, pp.47-60.

Wang, Guoquan. , 2013. "Millimeter-accuracy GPS landslide monitoring using Precise Point Positioning with Single Receiver Phase Ambiguity (PPP-SRPA) resolution: a case study in Puerto Rico". Journal of the Geodetic Society. 3(1). 10.2478/jogs-20130001.

Bellone, T., P. Dabove, A. M. Manzino \& C. Taglioretti, 2016. "Real-time monitoring for fast deformations using GNSS lowcost receivers", Geomatics, Natural Hazards and Risk, 7:2, 458470, DOI: 10.1080/19475705.2014.966867

Sanlioglu, Ismail \& Zeybek, Mustafa \& Yigit, Cemal, 2016. "Landslide Monitoring with GNSS-PPP on Steep-Slope and Forestry Area: Taşkent Landslide". In Proceeding of 2nd International Conference on Engineering and Natural Sciences.

Corominas, Jordi \& Moya, José \& Lloret, Antonio \& Gili, Josep \& Angeli, Maceo Giovanni \& Pasuto, Alessandro \& Silvano, S., 2000. "Measurement of landslide displacements using a wire extensometer". Engineering Geology. 55. 149-166. 10.1016/S0013-7952(99)00086-1.

Mirzaee, Sara \& Motagh, Mahdi \& Akbari, Bahman, 2017.'Landslide Monitoring using InSAR Time-series and GPS Observations, Case Study: Shabkola Landslide in Northern Iran". ISPRS - International Archives of the Photogrammetry, Remote 
Sensing and Spatial Information Sciences. XLII-1/W1. 487-492. 10.5194/isprs-archives-XLII-1-W1-487-2017.

Hosseini, Samira \& Azizi, A \& Bahroudi, Abbas \& Sharifi, Mohammad A., 2011. "Three dimensional landslide mapping with high resolution satellite images Cartosat". 32nd Asian Conference on Remote Sensing 2011, ACRS 2011. 1. 627-632.

Barbarella, Maurizio and Fiani, Margherita, 2013. "Monitoring of large landslides by Terrestrial Laser Scanning techniques: field data collection and processing", European Journal of Remote Sensing, Vol. 46, No.1, pp.126-151.

Lindner, Gerald \& Schraml, Klaus \& Mansberger, Reinfried \& Hübl, Johannes, 2015. "UAV monitoring and documentation of a large landslide". Applied Geomatics. 8. 10.1007/s12518-0150165-0.

Yaprak, Servet \& Susam, Tekin, 2018. "The Role of Unmanned Aerial Vehicles in Monitoring Rapidly Occurring Landslides", Geodetski list, Vol. 72 (95) No. 2, pp 113-132 .

Peppa, M. V., Mills, J. P., Moore, P., Miller, P. E., Chambers, J. E., 2016. "Accuracy Assessment of a UAV-based Landslide Monitoring System". ISPRS - International Archives of the Photogrammetry, Remote Sensing and Spatial Information Sciences, XLI-B5. 895-902.

Lindner, G., Schraml, K., Mansberger, R. et al., 2016. "UAV monitoring and documentation of a large landslide", Applied Geomatics, Vol.8, No. 1.

Mazzanti, P., Bozzano, F., Cipriani, I., Prestininzi, A., 2015. "New insights into the temporal prediction of landslides by a terrestrial SAR interferometry monitoring case study". Landslides, Vol.12, No.1, pp.55-68. 